THE INTERNATIONAL

REVIEW OF RESEARCH IN

OPEN AND DISTANCE LEARNING

\title{
Learning Management System Migration: An Analysis of Stakeholder Perspectives
}

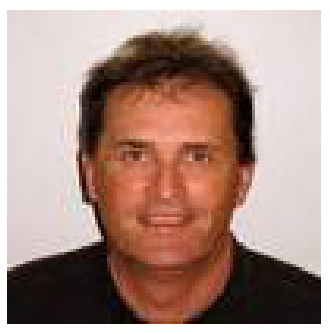

Thomas G Ryan, Mary Toye, Kyle Charron, and Gavin Park Nipissing University, Canada

\section{Abstract}

In this mixed methods study the authors describe the institution-level perceptions of stakeholders transitioning to a new learning management system (LMS). We address issues related to change, the institution's administration of the transition process, problems encountered, and realized learning via online survey data collection, analysis, and interpretation. We further detail results of a faculty survey, which sought to illuminate the LMS transition experience. The summation includes suggestions for institutions as they prepare for, and move through, foreseeable LMS change and transition.

\section{Introduction}

Emerging "in the mid-1990s. . Management systems have evolved from somewhat basic collections of disparate applications into intricate, integrated enterprise systems" (Leslie, 2003, p. 1). Alias and Zainuddin (2005) defined a learning management system (LMS) as "a software application or Web-based technology used to plan, implement, and assess a specific learning process" (p. 28). Mohawk College (2009) suggested an "L.M.S. can be broadly described as a web-accessible platform for the 'anytime' delivery, tracking and management of education and training. L.M.Ss are essentially software running on dedicated hardware" (p. 5). Some LMSs are now over twenty years old, and much has changed since the first LMS arrived on the distance education scene in the mid 1990 .

Over a period of 20 years a great deal of change and research has unfolded in all areas of distance education. Turner (2011) completed a meta-analysis of 695 studies, concluding that distance education research fits "into three main categories: (1) macro level research focusing on distance education systems and theories; (2) meso level research focusing on management, technology, and organization; and (3) micro level research focusing on teaching and learning in distance education" (p. 4). Our objective herein was to add to the macro 
and meso level by examining online instructor perceptions of our institution-level change of a learning management system (WebCT/Blackboard CE to Blackboard Learn version). To do this we undertook a research design and review of literature that would not only meet our needs but also frame our study.

Within the mixed methods research study, objectives included addressing issues pertaining to when, and why, such LMS transitions might occur, the dynamics of making the changes, this institution's management of the transition process, problems encountered, and lessons learned. This research built an informed awareness and overview of faculty by learning about their teaching background, years of experience, and LMS change experiences via survey and interview modes. Our research did not comment on micro-level issues by directly addressing teaching and learning; however, our focus was clearly directed towards our LMS as it changed and impacted technical staff and online instructors.

We reviewed several pertinent studies to learn what top features were supported by some LMSs and, in doing so, we became aware of the features and limitations within LMSs in general. Authors such as Colace, de Santo, and Vento (2003) completed evaluations, assessing 15 commercial LMSs, revealing two central aspects: online training services and course management attributes. Concurrently, Leslie (2003) concluded, "as a result of reviewing 45 CMS on 41 features, the researchers at Edutools were able to form a picture of some of the common and not so common features of these systems" (p. 6), which were listed as follows.

Table 1

Top 15 Features Supported across Products

\begin{tabular}{|l|c|c|}
\hline Feature name & $\begin{array}{c}\text { \# Products supporting fea- } \\
\text { tures }\end{array}$ & $\begin{array}{c}\text { Percentage of total (45) } \\
\text { products }\end{array}$ \\
\hline Discussion forums & 41 & $91.11 \%$ \\
\hline Registration integration & 41 & $91.11 \%$ \\
\hline Internal email & 39 & $86.67 \%$ \\
\hline Authentication & 38 & $84.44 \%$ \\
\hline Real-time chat & 34 & $75 \cdot 56 \%$ \\
\hline Orientation/help & 34 & $75 \cdot 56 \%$ \\
\hline Groupwork & 34 & $75 \cdot 56 \%$ \\
\hline Self-assessment & 34 & $75 \cdot 56 \%$ \\
\hline Course authorization & 34 & $75 \cdot 56 \%$ \\
\hline Automated testing and scoring & 34 & $75 \cdot 56 \%$ \\
\hline File exchange & 33 & $73 \cdot 33 \%$ \\
\hline Calendar/progress review & 33 & $73.33 \%$ \\
\hline Instructor helpdesk & 33 & $73 \cdot 33 \%$ \\
\hline Searching within course & 31 & $68.89 \%$ \\
\hline Student tracking & 31 & $68.89 \%$ \\
\hline Mean \# of products supporting a feature 29, Standard Deviation 8.72 & \\
\hline
\end{tabular}

(Leslie, 2003, p. 6) 
By looking at what had been the top features of past LMSs we were able to develop an informed and useful perspective and understanding. We discussed past research and decided that while these LMS features seemed adequate, innovation since 2003 has resulted in many more features being offered, hence the need to upgrade and transition as the LMSs evolve. We concluded, as others have, that "an effective LMS must support active engagement, meaningful connections between segments of the course, easy communication, and formative feedback on work that is presented in class discussions or through other venues" (Rubin, Fernandes, Avgerinos, \& Moore, 2009, p. 82). When some of these features are lacking or not as current as they should be, migration and transitioning can be expected, which can impact all stakeholders as the adjustment and change ensues. By focussing solely on the LMS we do not discount the importance of the instructor, who uses this LMS as a tool, or the background behaviour of the instructor, which can dictate the positive or negative outcomes associated with learning online, transitioning, and migration.

Stakeholders often include users, faculty, staff, and administration (Jafari, McGee, \& Carmean, 2006). These people may use terms such as best practices, which are bantered about and have deep roots in LMS research (Whitmyer, 2000). It could be that the reason for a change was related to basic system performance issues, such as increased demands on current LMSs, thus the need to move forward every few years, transitioning at what seems to users as a rapid pace (Jafari et al., 2006). Few researchers, and even fewer studies, have considered the turbulence, upset, and adjustments required when a LMS is upgraded from something that may be viewed as wanting or antiquated, by some, to one that is viewed as current. This transitioning sends various stakeholders into problem-solving mode as the unfamiliarity of the new LMS, and changes required, transfer stakeholders from the known into the unknown.

Smart and Meyer (2005) investigated faculty perceptions of LMS change and discovered "faculty, who would need to restore course content, that did not convert intact and accurately-will face increased workloads and frustration, should an institution choose to change from one LMS to another" (p. 69). Smart and Meyer also found that people "... are legitimately concerned about the time and effort needed to make the transition a success for their courses and students" (p. 70). Concern and research findings proved to be the impetus for us to look at our transitioning. Change is one of the top ten information technology (IT) issues (Allison, et al., 2008), and change management (Fullan, 2002) has made the list of institutional IT concerns for the first time in many institutions. Yet, behind any change are the stakeholders as the transitioning process is not just a hardware concern. Hulley and Dier (2005) discovered that leaders who are facilitating change need highly refined emotional intelligence skills in order to know how, and when, to press on, change direction, or back off (p. 21). Change management is about "developing a process for handling IT changes that are made on a regular basis (e.g., patches, upgrades, replacements) and that can be very disruptive if there is no change management process in place" (p.40). This change can occur simply as part of the product's evolving sophistication or when "institutions want a centralized system to assure uniformity of appearances and, if possible, to manage many other aspects of the course and overall administration" (Marsh, McFadden, \& Price, 1999). 
Whether to move to a new version or to a new product is not the issue because change is inherent in the use of technology (Finkelstein \& Pittinsky, 2003; Sclater, 2008). Indeed we "are still at the 'Model T' stage of LMS use" (Morgan, 2003, p. 12).

\section{Purpose}

In this exploratory mixed methods study we interviewed technical staff and surveyed instructors online who experienced the institution-level change of a learning management system (WebCT/Blackboard CE to Blackboard Learn version). We addressed issues pertaining to when, and why, such LMS transitions might occur, the dynamics of making the changes, this institution's management of the transition process, problems encountered, and lessons learned. This research was to serve as an awareness-building overview of the situation facing faculty and as a signal for institutions considering or planning this type of change. This study was an attempt to share the lessons learned at the authors' institution, which can be a starting point; some may suggest it is all about managing change effectively.

\section{Background: CMS and Change}

The use of a learning management system at our university has been evolving since the late 1990s. During this period we used distance education teleconferencing for courses in education and the arts and sciences. In the later part of the 1990's we recognized the potential of the software, and the campus's information technology people began an investigation of various applications (WebCT). Understanding that the choice should be faculty driven, we convened a faculty committee who reviewed leading products. After a lengthy review, the committee made its recommendation. The University negotiated a contract, developed a training program, and hosted and supported the system. Although initial faculty use was minimal, a slow but steady period of growth followed as more faculty began to use the software each semester for a variety of blended, teleconference, and online courses. This process was to be repeated in the late 1990 s and again in 2005 (WebCT).

In 2010, we repeated this process and after much discussion a new LMS was introduced to our campus, and faculty using the old LMS were given a semester to make the transition/ migration. Naturally, some faculty were unhappy about this change because users had devoted a good deal of time and effort learning the original LMS (Blackboard CE). They now needed to learn about a new LMS (Blackboard Learn) platform that was quite different from the one with which they were already familiar. This experience provided the campus with an important lesson on the changing dynamics of LMSs, and campus support staff was determined to manage the use and transition process to the best of their ability. We believe our system was akin to the one displayed in Figure 1, as follows. 


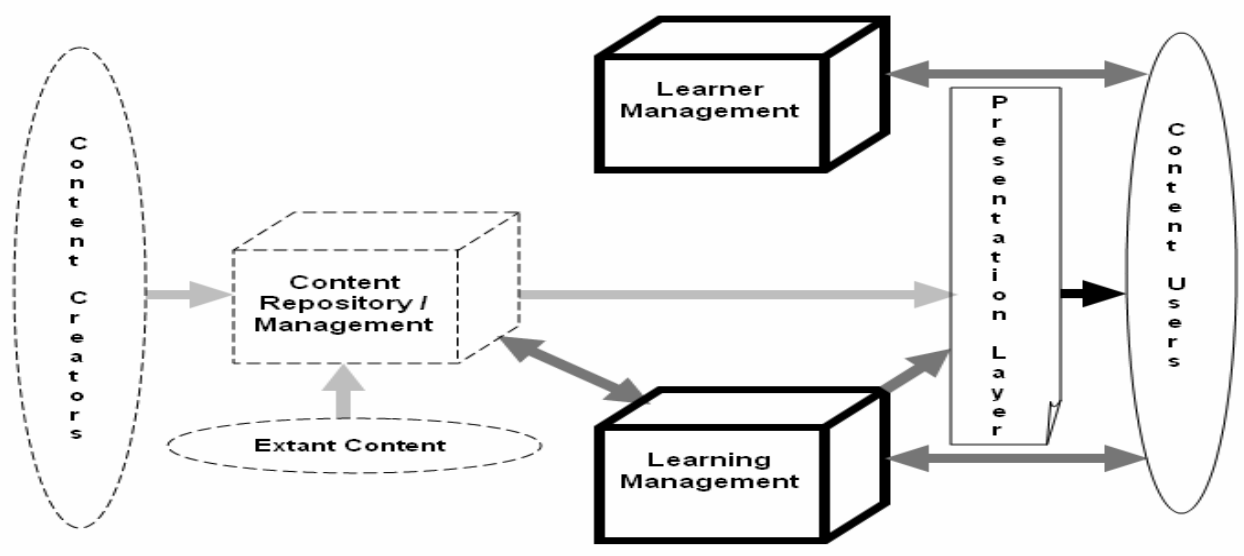

Figure 1. LMS Components (Irlbeck \& Mowat, 2005, p. 6).

\section{Method}

In January of 2010, academic and technology staff met to discuss issues and concerns related to the transition to the new CMS (Blackboard Learn from Blackboard CE). We met several times to record our thoughts on the course of action. During this month we also developed an ethics application and gained final approval, in May of 2010, for our study tentatively entitled, The Blackboard Jungle Research Panel. We located a survey tool online and requested permission to adapt it from Dr. Clayton at Middle Tennessee State University. Permission was received and our panel began adapting and piloting the 22 item survey, with a completed tool in place for June 2010 (Appendix). We decided to use kwiksurveys (http://www.kwiksurveys.com/) as this service was offered for no charge, and we could use it for several months to complete our work. We were able to send online invitations to all instructors, track responses, quantify, and examine (descriptive statistics) in table format (Microsoft Excel) via kwiksurveys. We also displayed results in a summative manner that facilitated analysis and interpretation as the survey data was filtered into easily read charts and tables, which are listed in the Results section.

Our discussion group transcripts were analyzed, and evidence was realized for this mixed methods study. To be clear, we understood "mixed methods designs evolved from the notion of triangulating the information from different data sources" (Tashakkori \& Teddlie, 2003, p. x). Hence, we collected interview, survey data, and anecdotal evidence via personal communications (email, voice mail, and face-to-face). Within the survey, there were opportunities for empirical (short answer) and long responses, which both enhanced the data and allowed for triangulation (Denzin, 1989). Admittedly, our study does not contain thick descriptions usually found within qualitative studies, yet "it does meet the minimum criteria spelled out in our definition. Therefore, we consider it an example of mixed methods research" (Creswell \& Plano-Clark, 2006, p. 11-12). 


\section{Results}

We concluded our online survey after three weeks with 51 respondents $(N=51)$. Analysis of demographic information allowed us to better understand the voices within the feedback which revealed our sample contained 21 males $(44 \% n=22)$ and 27 females $(56 \% n=$ 29). This sample of 51 was comprised of three new instructors who had not taught online previously and 16 participants, who had between one and five years of experience teaching online. We also determined that 23 participants had between five and ten years of online teaching experience. Even at this point, we concluded that the sample was mostly female and had online teaching experience at the university level. As for previous teaching experience at a level other than university, we found that 19 respondents had no previous experience outside the university. Five had between one and five years experience outside the university, and four had between five and 10 years of experience. Interestingly, 17 had over 10 years of experience outside of the university; hence, we deduced that our sample was largely an experienced group before they began teaching online.

The representative faculties and divisions broke down as follows: Arts \& Science, 14 (29\%), Education, 10 (21\%), Applied and Professional Schools, 16 (31\%), Distance (In-Service/AQ, $\mathrm{ABQ}), 8$ (16\%), Distance, (CCE) 3 (6\%). This breakdown resulted in a total of 51 participatory instructors. Note: Rounding of numbers resulted in totals over $100 \%$.

Our first item on our survey asked, To what extent did you use Blackboard CE (formerly WebCT) in your teaching?

Table 2

Responses to the Question about the Previous Use of Blackboard CE (formerly WebCT) to Teach

\begin{tabular}{|c|c|c|c|c|}
\hline Never & Seldom & Sometimes & Often & Very Often \\
\hline $22 \%(n=11)$ & $4 \%(n=2)$ & $12 \%(n=6)$ & $20 \%(n=10)$ & $44 \%(n=$ \\
$22)$
\end{tabular}

These responses led us to conclude that most had used the former LMS and only a minority were new users. Our next item on our survey asked, To what extent did you use Blackboard Learn in your teaching? 
Table 3

Responses to the Question about the Use of Blackboard Learn to Teach

\begin{tabular}{|c|c|c|c|c|}
\hline Never & Seldom & Sometimes & Often & Very Often \\
\hline $14 \%(n=7)$ & $4 \%(n=2)$ & $14 \%(n=7)$ & $18 \%(n=9)$ & $51 \%(n=26)$ \\
\hline
\end{tabular}

We found that our instructors were experienced, and most had used the Blackboard Learn platform very often prior to this survey (51\%). In fact when we asked, do you teach any fully online distance education courses? 27 respondents (53\%) told us they did and slightly less 24 (47\%) signalled that they had not. Of the $51 \%$ who had taught online we asked, how many course do you teach each year?

Table 4

Responses to the Question about Teaching Fully Online Distance Education Courses

\begin{tabular}{|c|c|c|c|c|}
\hline None & One Course & Two Courses & Three Courses & $\begin{array}{c}\text { Four } \\
\text { Courses }\end{array}$ \\
\hline $25 \%(n=13)$ & $8 \%(n=4)$ & $6 \%(n=3)$ & $6 \%(n=3)$ & $5 \%(n=3)$ \\
\hline
\end{tabular}

We found out that half of our instructors teach at least one course online and many teach more than one course per year.

We also asked, do you teach any hybrid/blended courses (using Blackboard features to supplement your face-to-face instruction)? Of our 51 respondents 23 (45\%) said yes, and 28 (55\%) said no, they did not teach any hybrid/blended courses using Blackboard features to supplement the face-to-face instruction.

\section{Training}

We asked if they had attended any Blackboard training, workshops, or demonstrations? Participants signalled that 19 (37\%) had, and a majority of 32 (63\%) indicated they had not attended any Blackboard training, workshops, or demonstrations. Specifically, 13 attended a workshop, one attended two workshops, and one attended three workshops. Following this question was an item that asked, have you consulted (in person, by e-mail, or by phone) with a technologist for Blackboard instruction? A majority of 48 (94\%) did consult (in person, by e-mail, or by phone) with a technologist.

\section{Transition}

We asked our sample if they believed they were well-informed about what they needed to 
do to transition courses from WebCT to Blackboard Learn.

Table 5

Responses to the Question about Being Well-Informed about How to Transition Courses

\begin{tabular}{|c|c|c|c|c|}
\hline Strongly Disagree & Disagree & Neither & Agree & $\begin{array}{c}\text { Strongly } \\
\text { Agree }\end{array}$ \\
\hline $9 \%(n=5)$ & $22 \%(n=11)$ & $38 \%(n=19)$ & $22 \%(n=11)$ & $9 \%(n=5)$ \\
\hline
\end{tabular}

Most of the sample (36) indicated that they did know if they were well informed or not, yet only a little over $20 \%$ suggested they were well informed, and the same signalled they thought they were not well informed. When we asked about the state of change, most indicated they were not frustrated with having to learn a new learning management system (CMS/LMS).

Table 6

Responses to the Question about Frustration Level about Having to Learn a New LMS

\begin{tabular}{|c|c|c|c|c|}
\hline Strongly Disagree & Disagree & Neither & Agree & $\begin{array}{c}\text { Strongly } \\
\text { Agree }\end{array}$ \\
\hline $13 \%(n=7)$ & $20 \%(n=10)$ & $36 \%(n=18)$ & $22 \%(n=11)$ & $9 \%(n=5)$ \\
\hline
\end{tabular}

Given the lack of concern while transitioning there also appeared to be an understanding of why Nipissing University moved to a new version of Blackboard (Learn).

Table 7

Responses to the Question about Understanding why the University was Moving to a New $L M S$

\begin{tabular}{|c|c|c|c|c|}
\hline Strongly Disagree & Disagree & Neither & Agree & $\begin{array}{c}\text { Strongly } \\
\text { Agree }\end{array}$ \\
\hline $9 \%(n=5)$ & $20 \%(n=10)$ & $33 \%(n=17)$ & $28 \%(n=14)$ & $11 \%(n=6)$ \\
\hline
\end{tabular}

Only $29 \%$ indicated they did not understand (strongly disagree + disagree) why Nipissing University moved to a new version of Blackboard. Overall the transition was 'smooth' for a majority of respondents (26). Keeping on a positive note we asked, what do you think 
were the most positive aspects of the transition to Blackboard Learn? Several respondents indicated, "It wasn't too difficult" and a few suggested, "I didn't really notice that there was a transition". One commented on "the functionality - The ability to embed video (YouTube/ other)" and many others noted how support staff were helpful, supportive and effective. In sum, many told us, "It provides a lot more options for discussion boards.".

Turning to the negative aspects of the transition we asked, what do you think were the most negative aspects of the transition to Blackboard Learn? One mentioned how "saving content from old system = migration issues" was a negative, and another instructor explained:

Discussion folder creation and maintenance is less intuitive in terms of labels, actions, modifications. There are so many choices (settings/permissions) in creating folders that it is more difficult to do it correctly, at least at first attempts. The interface seems relatively large and clunky (big icons - perhaps these can be resized?) Have not used it for a fully online course yet, but will be doing so in May so I hope it works well.

\section{Support}

With the transition we asked if the Nipissing support staff was very helpful in showing instructors how to use the newer version of Blackboard.

Table 8

Responses to the Question about the Helpfulness of Support Staff during the Transition Process

\begin{tabular}{|c|c|c|c|c|}
\hline Strongly Disagree & Disagree & Neither & Agree & $\begin{array}{c}\text { Strongly } \\
\text { Agree }\end{array}$ \\
\hline $11 \%(n=6)$ & $13 \%(n=7)$ & $15 \%(n=8)$ & $37 \%(n=19)$ & $\begin{array}{c}24 \%(n= \\
12)\end{array}$ \\
\hline
\end{tabular}

Of course we had to ask how they viewed the change as it unfolded; therefore, we put forward this unique statement: I would have preferred NOT to have learned how to use Blackboard Learn. As respondents indicated, they actually preferred learning how to use the new LMS. 
Table 9

Responses to the Question about Preferring Not to Have Learned How to Use Blackboard Learn

\begin{tabular}{|c|c|c|c|c|}
\hline Strongly Disagree & Disagree & Neither & Agree & $\begin{array}{c}\text { Strongly } \\
\text { Agree }\end{array}$ \\
\hline $37 \%(n=19)$ & $35 \%(n=18)$ & $22 \%(n=11)$ & $02 \%(n=1)$ & $\begin{array}{c}04 \%(n \\
=2)\end{array}$ \\
\hline
\end{tabular}

On another item concerning help and support over $65 \%$ of instructors indicated that support was good, while another $15 \%$ agreed help was neither good nor wanting. Only a minority of $20 \%$ (10) suggested the help was not up to the expected standard.

\section{Technical}

We wanted to know about some of the technical aspects so we asked, which browser program(s) do you usually use? A majority indicated they used Internet Explorer (26) or $46 \%$, followed by Firefox (17) or 30\%, then Safari (10) or 18\%, and lastly Google Chrome at (4) or $7 \%$. We wondered why the percentages added up to over 100 and decided that it was possible for instructors to use more than one browser to service online teaching. We looked deeper into browsers by asking, did you encounter any specific problems using Blackboard Learn with your usual choice of browser? Sixty-five percent (30) indicated no and $35 \%$ (16) signalled yes that they had problems with their browser. Participants were given an opportunity to provide short answers to further detail answers, and in the area of technical issues, one respondent suggested, they had "Java runtime errors as my version is newer than Blackboards. Google Chrome has issues ... I needed to use Firefox". Another commented, "Slower navigation overall - more frequent time-outs - extremely unreliable formatting control on posted messages - inability to attach multiple files to a posted message." Several commented on the pace of the LMS which was simply described as "slow." Some instructors recalled posting issues, such as the post not appearing for some students; however, this was linked to settings, such as moderation, and permissions, which was really within the domain of the instructor.

\section{Discussion}

\section{Problems and Positives}

As the transition was undertaken during September of 2010, we surveyed online to ascertain the types of success and problems encountered and to discover other issues. We also realized qualitative data within our interview transcripts, emails, and anecdotal evidence. Problems encountered during the transition fell into two categories (themes): technical and 
faculty issues. Given the many barriers that faculty typically encounter when working with instructional technologies (Brinthaupt, Clayton, \& Draude, 2009), it was not a surprise that there were several faculty-related behavioural and technical issues that emerged during the transition process. One administrative issue noted was the lack of compensation for the time required to convert courses from one LMS (form) to another. The university management decided at the beginning of the transition process that compensation was not available. This decision was upsetting for many, yet it was one instructors moved past as a matter of necessity to meet looming course start-date deadlines.

As well, many instructors suggested they had little time to revisit and redesign course materials, and some lacked an understanding of new instructional deadlines during the migration. These new timelines were attributed to additional time required by technical staff to act; and admittedly, for some faculty, making the transition in a timely fashion was a low-interest task. Faculty did not anticipate the time required to make their conversion and, as such, were frustrated when limited time remained. Time can be less an issue, we believe, if mandatory faculty training is established and available on a continual process (Nkonge \& Gueldenzoph, 2006). The type of training offered in our study included Blackboard orientation, workshops, and/or demonstrations. A minority of respondents $37 \%$ ( $n$ $=19$ ) did indeed make use of the opportunities to learn, however a large majority, $63 \%$ ( $n$ = 32) made no attempt to attend any Blackboard training, workshops, or demonstrations; this was something that was puzzling since, in doing so, problems and frustrations could be lessened, we believed.

Teaching online is, in many ways, best understood as "pedagogy empowered by digital technology" (Nichols, 2008), and this perception may illuminate a reason why only a minority of instructors (13 / 25\%) did attend a workshop, and just one participant attended two workshops; another participant attended three workshops. Of the several workshops available it was noteworthy to discover that only a few of our online instructors deemed this necessary. Perhaps this indicated decreased anxiety concerning change since we did have a majority of experienced instructors. However, most of our sample did make contact with a technologist for Blackboard instruction $(94 \%, n=48)$ in person, by e-mail, or by phone, which seemed to be a sign that perhaps the most convenient manner in which to remedy issues was that which seemed to fit the individual need of the instructor, whether it be in person, by e-mail, or by phone. Tallent-Runnels et al. (2006) reviewed several studies and concluded that all instructors and students need training and support within a LMS transition. For instructors, to not avail themselves of the offered training seems to be asking for frustration down the road.

Within our interviews some of the evidence gleaned by the transition team referred to new technical recommendations, the identification of "best practices," and the need for an increased emphasis on communication. Another realization was the need to focus less on administrative concerns and more on the instruction and learning area, within the LMS and the milieu in which it was to be utilized (Tallent-Runnels et al., 2006). Instructors further commented, "Tech support was freely available which helped allay my apprehensions," and we understood this as an indication of a level of confidence in the technical staff. On the 
technical side, the differences in the way certain learning resources converted to the new system led some instructors to conclude, "Marking tools are amazing," and "simply that it is a very easy program to use, very user friendly." The positive comments indicated a measure of satisfaction, yet training and encouragement remained a key feature for all for staff and faculty as they moved forward creating new curricula and standards within the newer LMS (Blackboard Learn). With more features and opportunities all stakeholders could widen the definition of "best practices" for online courses. Rubin et al. (2009) has stressed, "In teaching fully online courses, it is important that basic communication tasks be made simple for faculty and students, and automatic where feasible." Our communication was a prevailing factor leading some instructors to conclude, "I was truly thankful that I had tech support that was patient and accessible at all times when I first started. Thank you!" The migration was a positive move as one instructor suggested the new Blackboard Learn system has "more advanced features that allow us to better manage learning." There is however much criticism in the literature of all LMSs, and the fact that we used Blackboard forced us to consider that "Blackboard has limited tools to enable grouping across different kinds of tools (e.g., Discussion, and Assignments). This means that the elements needed for the week's work are spread across several pages, and require multiple clicks to access the materials ...” (Rubin et al., 2009, p. 83). Because our instructors may have only used Blackboard versions in previous years there was modest concern that, "other LMSs allow all learning elements and tools to be placed contiguously in a hierarchy or outline structure that visually represents the grouping" (Rubin et al.). What was clear was that we migrated successfully, and what was done has produced mostly positive results as students learn and faculty continue to instruct online.

\section{Conclusions and Recommendations}

This research was to serve as an awareness-building overview of the situation facing faculty and as a guide for institutions considering this type of change. As management systems continue to evolve, both instructors and site administration will need to adapt, change, and respond to the needs as they surface. LMSs can enhance access to educational opportunities while providing learning materials for students throughout a broad geographical area (Abrami et al., 2006). With the surfacing of innovative technologies, revisions to current systems, and changing needs and abilities of instructors, future LMS transitions are predictable. Each institution "must adapt, using technologies and models of understanding, in this case to reconcile teaching, research, IT, a changing environment, financial accountability and managerial models" (Wise \& Quealy, 2006, p. 4). By taking a prudent, informed approach to moving faculty forward and helping them make the change, we have begun to generate an enhanced understanding of this migration.

The data herein suggest there is much more to do; for instance, some faculty did not appear to adequately comprehend the need for migration to a new LMS. Perhaps these are people who do not like change, and any disruption would be viewed as unnecessary. As well, our survey data did not suggest that those who attended training sessions were less frustrated. Nonetheless research has indicated, and we believe, training should always be 
offered, whether mandatory or not.

As for recommendations, we realized two types: those from the survey (via the instructors) and our own. Our instructors suggested the following:

- Make available tutorial sessions that are face-to-face (not an online self workshop).

- Involve the instructors and implement their suggestions. We should have more control over content and updating information.

- More support, more training, and more student training.

- Ensure (hardware) servers work ALL the time.

- Roll out well in advance of September with pilot testing of changes.

- Ask instructors for input concerning what is needed; specifically, what did not work with the old version and what did work well with the old version.

- Continue to offer easy-to-access technology support and continue to hire staff to meet growing demands and growth.

Our own recommendations developed in a reflective manner as we reviewed our data and collectively decided what our next steps would be. We did this to continue to monitor, respond to, and change the system in a professional and strategic manner that infused the professional development of our team. Hence, for continued growth we decided to do the following:

- Continue to survey instructors each semester (pre/post).

- Survey students as an exit or entry item to create a 360 loop of information.

- Survey IT staff to gain insight and align this with student and instructor surveys.

- Provide an online suggestion box for 24/7 input.

- Form a University-wide steering committee.

- Provide training for instructors through a centre for flexible teaching and learning. 


\section{References}

Abrami, P.C., Bernard, R.M., Wade, A., Schmid, R.F., Borokhovski, E., \& Rana Tamim, R.(2006). A review of e-learning in Canada: A rough sketch of the evidence, gaps and promising directions. Canadian Journal of Learning and Technology, 32(3). Retrieved from http://www.cjlt.ca/index.php/cjlt/article/view/27/25.

Alias, N. A., \& Zainuddin, A. M. (2005). Innovation for better teaching and learning: Adopting the learning management system. Malaysian Online Journal of Instructional Technology, 2(2), p.27-40.

Allison, D.H., P.B. DeBlois, \& the EDUCAUSE Current Issues Committee. (May/June 2008). Top 10 IT issues 2008. EDUCAUSE Review, 37-61.

Brinthaupt, T. M., Clayton, M. A., \& Draude, B. J. (2009). Barriers to and strategies for faculty integration of IT. In P. Rogers, G. Berg, J. Boettcher, C. Howard, L. Justice, \& K Schenk (Eds.), Encyclopedia of distance learning ( $2^{\text {nd }}$ ed. pp. 138-145). Hershey, PA: IGI Global.

Creswell, J. W., \& Plano-Clark, V.L. (2006). Designing and conducting mixed methods of research. Thousand Oaks, CA: SAGE Publications.

Colace, F., De Santo, M., \& Vento, M. (2005). Personalized learning path based on metadata standards. InternationalJournal on E-Learning, 4(3), 317-335. Norfolk, VA: AACE. Retrieved from http://www.editlib.org/p/4820.

Denzin, N. K. (1989). The research act: A theoretical introduction to sociological methods. Englewood Cliffs, NJ: Prentice Hall.

Finkelstein, J., \& Pittinsky, M. (2003). The evolving role of course management systems providers in the transformation of education: An interview with Blackboard's Matthew Pittinsky. The Technology Source. Retrieved from http://technologysource. org/article/evolving role of course management system providers in transformation of education/

Fullan, M. (2002). Change forces with a vengeance. London: Routledge-Falmer.

Hulley, W., \& Dier, L. (2005). Harbours of hope: The planning for school and student success process. Bloomington: National Educational Service.

Jafari, A., McGee, P., \& Carmean. C. (Jul/Aug 2006). Managing courses defining learning: What faculty, students, and administrators want. EDUCAUSE Review, 41(4), pp. 50-52, 13 pp.

Leslie, S. (2003). Important characteristics of course management systems: Findings from the Edutools.info project. Retrieved from http://www.island.net/ leslies/blog/ stories/2003/o6/13/importantCharacteristicsOfCmsFindingsFromEdutools.html 
Marsh, G. E., A. C. McFadden., \& B. J. Price. (Fall 1999). An overview of online educational delivery applications. Online Journal of Distance Learning Administration, II( II). Retrieved from http://www.westga.edu/!distance/marsh23.html .

Mohawk College. (January 2009). Final report of the LMS project. Retrieved from http:// lmsreview.mohawkcollege.ca/docs/LMSreviewFinalReport ModifiedBrief.pdf

Morgan, G. (May 2003). Faculty use of course management systems. ECAR Key Findings. EDUCAUSE Center for Applied Research, 2. Retrieved from http://net.educause. edu/ir/library/pdf/ecar_so/ers/ers0302/ekfo302.pdf.

Nichols, M. (2008). E-Learning in context. Retrieved from http://akoaotearoa.ac.nz/sites/ default/files/ng/group-661/n877-1---e-learning-in-context.pdf

Nkonge, B., \& Gueldenzoph, L. E. (2006). Best practices in online education: Implications for policy and practice. Business Education Digest, 15, 42-53.

Rubin, B., Fernandes, R., Avgerinos, M.D., \& Moore, J. (January 2009). The effect of learning management systems on student and faculty outcomes. The Internet and Higher Education , 13(1-2), 82-83.

Sclater, N. (June 2008). Web 2.0, personal learning environments and the future of learning management systems. EDUCAUSE Center for Applied Research, Volume 2008, 13. Retrieved from http://connect.educause.edu/Library/ECAR/Web2oPersonalLearningEnvi/46952.

Smart, K. A., \& K. A. Meyer. (2005). Changing course management systems: Lessons learned. EDUCAUSE Quarterly, 2, 68-70.

Tashakkori, A., \& Teddlie, C. (Eds.). (2003). Handbook on mixed methods in the behavioral and social sciences. Thousand Oaks, CA: Sage Publications.

Tallent-Runnels, M.K., Thomas, J.A., William Y. Lan, W. Y., Cooper, S. Ahern, T.C., Shana \& Shaw, S.M. (2006). Teaching courses online: A review of the research. Review of Educational Research, 76, 93-135. doi: 10.3102/00346543076001093.

Turner, S.A. (2011). A self-study of technological transition: Instructional impacts of shifting a distance course delivery system. The Journal of Educators Online, 8(2), 1-24.

Whitmyer, C. (2000). Comparative features analysis of learning course management software. University of the Future, LLC.

Wise, L., \& Quealy, J. (2006). LMS governance project. Retrieved from University of Melbourne, Information Services Web site: http://www.infodiv.unimelb.edu.au/ telars/talmet/melbmonash/media/LMSGovernanceFin alReport.pdf 


\section{Appendix}

We need some information about your familiarity with Blackboard CE and Learn and your use of Blackboard in your courses.

1. To what extent did you use Blackboard CE (formerly webCT) in your teaching? (Please circle the appropriate number.)

$\begin{array}{ccccc}1 & 2 & 3 & 4 & 5 \\ \text { Never } & \text { Seldom } & \text { Sometimes } & \text { Often } & \text { Very Often }\end{array}$

2. To what extent have you used Blackboard Learn in your teaching?

$\begin{array}{ccccc}1 & 2 & 3 & 4 & 5 \\ \text { Never } & \text { Seldom } & \text { Sometimes } & \text { Often } & \text { Very Often }\end{array}$

3. Do you teach any fully online distance education courses? How many

$\begin{array}{rr}1 & 2 \\ \text { Yes } & \text { No }\end{array}$

4. Do you teach any hybrid/blended courses (that use Blackboard features to supplement your face-to-face instruction)?

$\begin{array}{rr}1 & 2 \\ \text { Yes } & \text { No }\end{array}$

5. Have you attended any Blackboard training workshop or demonstrations?

12

If yes \#_ Yes $\quad$ No

6. Please indicate your gender (with an "X"): female male

7. Please indicate the number of years you have taught at the University level: years other

8. Please indicate your faculty: Arts \& Science Education. Professional Schools

CCE In-Service Education (ABQ,AQ 
For the remainder of the survey, please rate each of the items using the following response scale. Be sure to write in a number for each item.

$\begin{array}{rrrrr}1 & 2 & 3 & 4 & 5 \\ \text { strongly } & \text { disagree } & \text { neither agree } & \text { agree } & \text { strongly } \\ \text { disagree } & & \text { nor disagree } & \text { agree }\end{array}$

1. I was well-informed about what I needed to do to transition my courses from WebCT to Blackboard Learn.

2. I was frustrated with having to learn a new course management system.

3. I understand why Nipissing University moved to a new course management system.

4. The Nipissing support was very helpful in showing me how to use Blackboard.

5. I would have preferred not to have learned how to use Blackboard Learn.

6. The amount of time given for the transition to Blackboard was appropriate.

7. When I needed help in learning Blackboard, I was able to obtain that help quickly.

8. Overall, my transition to using Blackboard was a smooth one.

The remaining questions are open-ended. Please provide as much detail as you wish for these items.

1. What do you think were the most positive aspects of the transition to Blackboard Learn?

2. What do you think were the most negative aspects of the transition to Blackboard Learn?

3. Do you have any recommendations for how Nipissing should manage the transition to a new course management system in the future?

Thank you for your help! As mentioned earlier, we intend to take your feedback very seriously as we change and evolve. 


\section{Athabasca University}

(c) (i) 